\title{
Back to the Basics: How Feelings of Anger Affect Cooperation.
}

\section{STRUCTURED ABSTRACT}

Purpose: We examine single-round cooperation when both parties are angry. We propose that angry individuals, who are much more likely to consider the emotional state of their partner than are neutral individuals, apply a lay theory dictating that anger decreases cooperation and react accordingly by lowering their own level of cooperation.

Design/Methodology/Approach: We report four experiments involving different samples, manipulations, payment schemes, and interfaces. Our methodological approach was to capitalize on the positives of experimental research (e.g., establishing causality), while also trying to conceptually replicate our findings in different settings.

Findings: We found evidence for a lay theory (i.e., expectation) that anger decreases cooperation, but that actual cooperation was lowest when angry individuals were paired with other angry individuals, supporting our hypotheses.

Research implications/limitations: Anger can spill over from unrelated contexts to affect cooperation, and incidental anger by itself is not enough to decrease cooperation. However, our findings are limited to anger, and cannot necessarily be used to understand the effects of other emotions.

Practical implications: Before entering into a context that requires cooperation, such as a negotiation, be wary of the emotional state of both yourself and of your partner. Our research suggests that only if both parties are angry, then the likelihood of cooperation is low.

Originality/value: To the best of our knowledge, we are the first researchers to address the question of how incidental anger affects single-round cooperation. By going back to the basics, we believe our findings fill a gap in existing research, and offer a building block for future research on anger and cooperation.

Keywords: anger; cooperation; lay theories; public goods game 


\section{INTRODUCTION AND CONCEPTUAL DEVELOPMENT}

Scholars have long noted the critical role of cooperative behavior in the survival of organizations (Barnard, 1938; Wagner, 1995) and avoiding relationship conflict (De Dreu and Weingart, 2003). Managers and employees have recognized the value of cooperation, defined as joint action for mutual benefit (Dugatkin et al., 1992; Stephens and Anderson, 1997), in maintaining friendly ties, undergoing successful mergers and acquisitions, and achieving high performance (La Porta et al., 1997; Luo, 2002; Schermerhorn, 1975). The financial gains from cooperation can be substantial. For example, Bae and Insead (2004) found that interfirm cooperation significantly facilitated access to scarce resources in the telecommunications industry.

Researchers have sought to identify the primary precursors to cooperation. By pinpointing antecedents, scholars can better recognize those that increase cooperative behavior, thereby potentially facilitating negotiations, building interpersonal relations, and benefiting organizations. One antecedent, emotion, has received much attention from scholars (De Hooge et al., 2007; DeSteno et al., 2010; Montes et al., 2012; Nair, 2008; Posthuma, 2012; Syna Desivilya and Yagil, 2005; Wubben et al., 2009).

Several studies have used the Emotion as Social Information (EASI) model as an overarching framework for examining the relationship between emotions and cooperation, as do we (Van Kleef, 2010; Van Kleef et al., 2010). The EASI model captures how emotional expressions shape social interactions and decisions. In a social context that requires reaching a decision among two or more individuals, decision makers use both their own and their partner's emotions as cues. These cues are used to make sense of a "fuzzy" situation in which the motivations, goals, and thoughts of the other partner are generally unclear, and are ultimately 
used to influence the final decision.

According to the EASI model, there are two ways in which one partner's emotional state can affect the other's decision making process. The first, the affective process, stipulates that each participant "catches" the emotional state of the other so that both feel the same way (for a broader review on emotional contagion see Hatfield et al., 1994). This process usually occurs in face-to-face situations where the partners have extensive contact, and mimic the facial expressions, body language, vocalizations and verbal expressions of their partner. The second process, the inferential process, refers to strategically using the information provided by the partner's emotional expressions to inform one's own decision. In the present studies, the two partners involved in the decision making process were not face-to-face, and received only limited verbal information regarding the other's emotional state. Thus, we limit our scope to inferential processes.

In examining emotion and cooperation, we focus specifically on anger. Anger has received special attention for several reasons. First, it is one of the most frequently experienced emotions in the workplace (Fitness, 2000), as well as in daily life (Averill, 1982; Shimanoff, 1984). Second, it has an unusual ability to capture the attention of both the person experiencing it and others observing it, above and beyond the attention given to other negative emotions (Hansen and Hansen, 1988; Lerner and Tiedens, 2006). Third, it can narrow one's focus solely to the anger-inducing event or object such that it becomes more difficult to consider other factors, such as situational constraints (Gable et al., 2015; Harmon-Jones et al., 2013; Tiedens and Linton, 2001). Fourth, it can spill over from past situations to affect current judgments, decisions and interactions unrelated to the anger-inducing event (Kugler et al., 2010). Finally it is often experienced more intensely than other emotions (e.g., sadness), and can result in aggressive or 
otherwise inappropriate behaviors with significant negative consequences for the organization (Felson, 1992; Glomb, 2002). Indeed, according to Van Kleef (2010, p. 545), "Of the range of emotions that may arise in conflict, anger is perhaps the most prominent and pervasive [...] For a thorough understanding of the dynamics of conflict resolution and escalation, it is therefore crucial to know how parties in conflict are influenced by their own and others' anger." For these reasons, we chose to delve more deeply into the relationship between anger and cooperation.

The majority of prior research either (1) involves cooperation that is embedded within a complex negotiation or multi-round bargaining process (e.g., Van Kleef et al., 2004a), or (2) involves anger that is embedded within that negotiation or bargaining process (also known as integral anger; Sinaceur and Tiedens, 2006). Usually both occur simultaneously (e.g., Adam et al., 2010; Butt et al., 2005; Overbeck et al., 2010; Van Beest et al., 2008; Van Dijk et al., 2008; Van Kleef and Côté, 2007; Van Kleef et al., 2004b). Such research is important because it mirrors real-world situations where making decisions involves back-and-forth communication and responding to another's anger that can surface during the process.

However, there are two limitations to this approach. First, examining anger within such complex highly interdependent settings provides limited insight into the basic fundamental relationship between anger and cooperation. Second, examining only integral anger limits the ability to pinpoint which specific aspect of the emotional experience is affecting cooperative behavior. We hope to address both of these limitations and further our understanding of the role that anger plays in influencing cooperation.

In the present context, integral anger refers to anger that arises within the negotiation setting (Cavanaugh et al., 2007), such as anger that arises from an insultingly low offer. Incidental anger refers to anger that arises completely outside the negotiation setting (Cavanaugh 
et al., 2007), such as anger that arises from an argument with a family member. It is important to examine incidental anger in addition to integral anger for at least two reasons. First, research has shown that incidental anger can "spill over" from previous situations to affect decisions in an entirely new situation (Bodenhausen et al., 1994; Dunn and Schweitzer, 2005; Harlé and Sanfey, 2007; Kugler et al., 2010; Williams and Alliger, 1994). Thus, research would suggest that anger arising from an argument with a family member can spill over to affect cooperation in situations with completely different people, norms, structures, standards, locations, etc. Second, examining incidental anger allows researchers to divorce the pure feelings of anger from other situational factors since the two situations are entirely separate. With integral anger, it is less clear which aspect of the anger experience is influencing cooperation - is it the feeling of anger or another situational factor? For example, a negotiator could get angry when his or her counterpart makes an insultingly low offer, and decrease his or her subsequent cooperation. It could be that the feelings of anger are driving the low cooperation, or it could be the motivation for revenge, or both. In the present studies, we hope to disentangle these effects. Specifically, we aim to find out how feelings of anger, unconfounded with any other variables, influence cooperation. This distinction has important implications. For instance, if the negotiator's anger is the result of the counterpart's previous offer (integral anger), the counterpart might react by improving or modifying that offer. However, if the anger is the result of some external event (incidental anger), then perhaps a more generalized anger-management strategy, such as proposing a short break, might be called for.

We also aim to examine anger in a simple, single-round, one-shot cooperation task, where the task ends after one move by each party. As mentioned, previous research on integral anger and cooperation has focused primarily on complex interdependent multi-round 
negotiations or back-and-forth bargaining. Doing so has supplied great insight into the relationship between anger and cooperation. For instance, several of these studies have identified how the emotion of a counterpart matters, and how to respond in the most strategic way possible (e.g., Côté et al., 2013; Lelieveld et al., 2011; Lelieveld et al., 2012; Wang et al., 2012).

However, we feel that this focus has unintentionally overlooked the fundamental relationship between anger and cooperation, which may not mirror that found in more complex interdependent tasks. Specifically, we argue that in multi-round negotiations where individuals have to interact extensively and continuously respond to one another's offers, each individual is much more likely to take the other person's emotional state into consideration. Said otherwise, when one's original decisions/offers significantly hinge or depend on another person's decisions/offers there is a greater chance that the individual will take the emotion of the other person into consideration because emotion serves as an important source of information (as specified by the EASI model). This idea has been captured by the phrase "shadow of the future", which refers to the degree to which parties anticipate that a relationship will continue into the future (Axelrod, 1984). Such research has shown how different parties' decisions change depending on the extendedness of the relationship. In situations where there the shadow of the future is weak - where individuals do not interact extensively with one another - there is probably a significantly lower likelihood that an individual will take the emotional state of the other person into consideration when making a decision/offer. This type of situation is not uncommon in organizations (Heide and Miner, 1992). For example, in a multi-round negotiation, an actor facing an angry opponent might concede early to avoid a string of potentially unpleasant exchanges. No such consideration arises in single-play tasks.

All told, it is unclear how feeling angry, by itself, affects cooperation in a situation where 
there is no shadow of the future. In seeking an answer to this question we propose that lay theories of cooperation and anger's other-orientation are important parts of the puzzle. In doing so, we hope to take a step back and determine the extent to which incidental anger affects cooperation in simple situations.

The paper is organized as follows: First, we discuss why there is likely to be a widelyheld expectation or lay theory that angry people are not cooperative. Second, we provide evidence that anger is an other-oriented emotion. Taken together these two propositions suggest that, in a single-round cooperation task, cooperation will be lowest when angry individuals are partnered with other angry individuals, as an angry individual will (a) be more likely to consider the other person's emotional state (other-orientation), (b) apply a lay theory that angry others are uncooperative, and (c) behave accordingly by reducing cooperation. The empirical portion of the paper examines these hypotheses across four studies. The final section places our findings in the context of the existing literature, and suggests theoretical and practical implications.

\section{Lay Theories of Anger and Cooperation}

The EASI model draws attention to the inferential process by which knowledge of a partner's emotional state might be used to predict how he or she will act, and thus to shape one's own behavior. The application of a lay theory is one way to glean a partner's likely behavior. Lay theories are coherent, structured sets of beliefs or expectations about a domain or object in one's environment (Zammuner, 2000) ${ }^{[1]}$. In this context, individuals have lay theories, or general expectations, about how other people experiencing different emotions are likely to act in general. They may then apply this lay theory to the specific situation at hand.

There is reason to believe that there is an expectation for angry people to be less cooperative than neutral people (though whether such beliefs are accurate is up for debate). 
This expectation stems from a variety of different sources. For example, we often associate anger with aggression, which is defined as behavior directed toward another individual that is carried out with the immediate intent to cause harm (Anderson and Bushman, 2002) and thus eminently uncooperative. Anger is often regarded as a necessary component of reactive aggression (Roland and Idsøe, 2001). Van Kleef (2010) also notes the positive relationship between anger and aggression. We also tend to portray angry individuals as more likely to be "rule-breakers", or less likely to adhere to societal norms, one of which is cooperation (Ashton-James and Ashkanasy, 2008; Fehr and Fischbacher, 2004). In addition, as angry individuals have likely just been offended by another person (Van Kleef and Côté, 2007), we often expect that they will be less prone to cooperating with others in the future, with the intention of avoiding another offensive confrontation. Similarly, anger often arises as a result of perceived injustice (Barclay et al., 2005). This perception can trigger retaliation against another party partly to "balance the scales" (Baron et al., 1999; Fox and Spector, 1999), again an act that is eminently uncooperative. Indeed, Cooper et al. (2015) report that people expect trait anger and hostility to be associated with low cooperation and high competition. We hypothesize:

Hypothesis 1: In a two-person, single-round cooperation task, there will be an expectation that angry partners cooperate less than neutral partners.

\section{Anger as an Other-Oriented Emotion}

Regardless of an individual's expectations about a partner's emotional state, these expectations will have little effect unless the individual actually considers them when making a decision. We propose that anger may play a second role in the process by influencing the individual's "other-orientation", the degree to which individuals consider the role of other 
people in their judgments and decisions (Allred et al., 1997). The idea of "other-orientation" derives from the appraisal theory of emotion, which proposes that emotions reflect changes in our cognitive evaluation of the environment (Smith and Ellsworth, 1985). This evaluation has been coined an appraisal (Lazarus, 1991), and refers to an interactive process that both detects and analyzes an event in relation to one's goals, beliefs, and values (Moors et al., 2013). The appraisal theory of emotion (Ellsworth, 2013) associates anger with the appraisal that another person is responsible for one's misfortunes and future events (not, for instance, situational factors). Thus, angry individuals are more aware of and sensitive to other people in the immediate environment than are neutral individuals (Smith and Ellsworth, 1985).

Indeed, past empirical research suggests that angry individuals are more otheroriented than neutral individuals. Allred et al. (1997, p. 175) explicitly described anger as an “other-directed emotion”. Similarly, Keltner et al. (1993) argued that anger magnifies the salience of other individuals, and that this should incline angry individuals to give more weight to others as causal agents in new situations. They found that angry individuals perceived negative events as more likely caused by people, while sad people perceived them as more likely caused by situations. Nesse (1990) stated that angry individuals are more likely to be attuned to the behaviors of others to avoid being insulted or offended again in the future. Similarly, Van Kleef et al. (2004a) asserted that an opponent's emotions have an impact on the focal individual only when he or she is motivated to allocate cognitive resources to consider them.

In sum, according to lay theories of emotion, there should be an expectation that angry individuals are less cooperative than neutral individuals. In line with research on otheroriented emotions, angry individuals are more likely to consider the emotional expressions of 
their partners when making their decisions than are neutral individuals. Bridging the research on lay theories and other-orientation, we propose that angry individuals, who are more likely to consider the role of others in their decisions, are more likely to actually apply their lay theories to predict and adapt to the other's behavior (i.e., "How is this other person's behavior likely to be affected by his or her emotional state?") than are neutral individuals. This suggests that angry individuals should cooperate less with other angry individuals (whom they expect to be non-cooperative) than they do with other neutral individuals (whom they do not expect to be non-cooperative). This is, of course, consistent with the sizeable literature showing that people often base their own decisions on their expectations of how others will behave (also known as conditional cooperation; Camerer, 2003). Thus, we hypothesize that:

Hypothesis 2: In a two-person, single-round cooperation task, there will be an interaction between the partners' emotional states such that cooperation is lowest when both partners are angry.

\section{OVERVIEW OF METHODS}

We report two pairs of studies testing these hypotheses. In the first pair, Study 1a tests Hypothesis 1, Study $1 \mathrm{~b}$ tests Hypothesis 2 . The second pair of studies serve as conceptual replications examining the same conceptual issues but with modified procedural details. Study 2a tests Hypothesis 1, Study 2b tests Hypothesis 2. Conceptual replications refer to repetitions of a test of a hypothesis or a result of earlier research work with different methods (Schmidt, 2009). The purpose of conceptual replications is to establish stability in findings (Popper, 1959; Radder, 1996). The issue of replicability of findings is important (Hunter, 2001; Nosek et al., 2015). Repeated testing also allows for identifying artifacts and 
chance findings. Thus, we took the opportunity to introduce some minor variants of possible nuisance variables such as participant pool, method of manipulating anger, type of interface (in-person versus online), and size of monetary incentives to probe the robustness of the findings.

\section{METHODS}

Our experimental task is a single-play two-person public goods game (SPPG; Fehr and Gächter, 2000; Kurzban and Houser, 2001; Marwell and Ames, 1979). In this game each participant receives an initial money endowment and can then either cooperate by contributing some or all of the initial endowment to a shared pool, or not cooperate by not contributing. Any money contributed to the common pool is enhanced by the experimenter (typically by multiplying the total by 1.5) and split equally between the participants. For example, if each participant receives a $\$ 10$ endowment and both contribute it all, both will profit from their cooperation by receiving $\$ 15$. However if one contributes and the other withholds, the withholder profits more (keeping the initial endowment and half of the \$15 pot for a total of $\$ 17.50$ ) and the contributor earns only the $\$ 7.50$ from the split pot. If both withhold, each receives only the $\$ 10$ endowment. Cooperation, in short, serves both actors well, but only if both cooperate and resist the temptation to take advantage of their partner. If both succumb, both lose (Andreoni, 1995). This game has been used extensively in studying cooperative behavior (Bornstein and Erev, 1994; Fischbacher et al., 2001; Hauert et al., 2002; Keser and Van Winden, 2000; Santos et al., 2008; Wagner, 1995). We focus on relationships in which partners had no prior interaction with each other and play only once. 


\section{Study 1a}

This study examines whether participants' own emotional state and knowledge of their partners' emotional state affect expectations of contribution in a SPPG.

\section{Participants and Procedure}

107 adult undergraduate students participated in this study $\left(46 \%\right.$ female, $\mathrm{M}_{\mathrm{age}}=20.49$ years). Participants were randomly assigned to one of four conditions in a 2 (own emotion) $\times 2$ (emotion of partner) between-subjects design: (a) neutral induction with a neutral partner, (b) neutral induction with an angry partner, (c) anger induction with a neutral partner, or (d) anger induction with an angry partner. Participants first completed an emotion induction, followed by a manipulation check. They then read a detailed description of the SPPG and were asked to predict how much the other anonymous player would contribute to the shared pool. The entire experiment was completed across several sessions in an enclosed laboratory with 40 carrels that prevented interaction with other participants.

Self-emotion manipulation. Anger was experimentally induced by the writing task developed by Strack et al. (1985) and validated in multiple studies since (Bodenhausen et al., 2000; DeSteno et al., 2004; Dunn and Schweitzer, 2005; Fessler et al., 2004; Huntsinger, 2013; Keltner et al., 1993; Kugler et al., 2010; Lerner and Keltner, 2001; Milkman, 2012; Motro et al., 2015; Norton and Gino, 2014; Tiedens and Linton, 2001; Todd et al., 2015). Participants were asked to write in detail (at least three paragraphs) about a time when they vividly experienced anger. They were asked to imagine how the specific emotion felt, to describe the experience of the emotion, and to avoid including any other feelings in their descriptions. In the neutral condition, participants were asked to describe in detail the last classroom they were in. In both conditions, participants were given as much time as they needed to write at least three 
paragraphs.

Manipulation check. After completing the writing task, participants rated the degree to which they were currently experiencing 20 emotion adjectives on scales ranging from (1) Do not feel at all to (9) Feel stronger than I ever have. Three items $(\alpha=.89)$ measured anger (irritated, mad, and angry); the remaining items were fillers (e.g., afraid, sad, happy). For similar procedures see Dunn and Schweitzer (2005) and Kugler et al. (2010).

Other-emotion manipulation. Each participant was told that he or she had been randomly paired with another actual participant who was also taking the study at the same time in the same room. All participants were told that their identity and their partner's identity would remain anonymous, except for one specific item of information about their partner's emotional state. This information was presented in the same way across all conditions: "Here is the information about the person you are paired with". Participants in the other-anger condition read: "current feeling: anger", while those in the other-neutral condition read: "current feeling: neutral".

Expectations of other's contribution. The dependent variable was measured by a single question: "How much money do you expect the other person to put into the shared pot?", with possible responses ranging from $\$ 0$ to $\$ 10$ (with no option of entering fractions).

\section{Results}

Manipulation check. Participants in the anger conditions reported feeling significantly more anger $(M=4.60, S D=2.14)$ than participants in the neutral conditions $(M=2.86, S D=$ 1.84), $F(1,105)=20.37, p<.001$, attesting to the effectiveness of our manipulation.

Expectations of other's contribution. We submitted the expected contribution of the other participant to a $2 \times 2$ between-subjects ANOVA. See Table 1 for means and standard 
deviations. There was a main effect of other-emotion, $F(1,103)=17.28, p<.05, \eta^{2}=.15$, such that participants expected angry individuals to be significantly less cooperative than neutral individuals. There was no significant effect of self-emotion, $F(1,103)=.88, n s$, and no significant interaction, $F(1,103)=.52, n s$. This supports Hypothesis 1 .

\section{---INSERT TABLE 1 HERE---}

\section{Discussion}

These results indicate that there is a common expectation that angry people are less cooperative than emotionally neutral people. Interestingly, this belief is not conditional on the emotional state of the participant making the prediction: It is held equally by both neutral and angry predictors. Our larger interest, of course, is in whether or not this belief is supported in actual behavior, and whether angry people paired with other angry people is the least cooperative dyad. We conducted Study 1 b using the exact same methodology, with the exception of offering actual incentives as opposed to hypothetical ones. This allows us to directly compare the predicted contribution levels from Study 1a with actual real-money contributions.

\section{Study 1b}

\section{Participants and Procedure}

185 adult undergraduate students participated ( $43 \%$ female, $M_{\mathrm{age}}=20.85$ years $)$. As in Study 1a, they were randomly assigned to one of four conditions in a 2 (own emotion) $\times 2$ (emotion of partner) between-subjects design. They first completed an emotion induction, followed by a manipulation check and then participated in a SPPG with another anonymous participant. As in Study 1a, the experiment was completed in several sessions in an enclosed laboratory with 40 carrels that prevented interaction with other participants.

Self-emotion manipulation. Both anger and a neutral state were experimentally induced 
using the writing task from Study 1a.

Manipulation check. We used the same manipulation check employed in Study 1a, averaging the anger items $(\alpha=.90)$.

Other-emotion manipulation. We used the same manipulation from Study 1a.

Contribution. Participants completed the SPPG described in Study 1a but with real money payoffs. Each participant began the game with $\$ 10$. They then had the opportunity to put any portion of the money into a shared pot, which would be multiplied by a factor of 1.5 and split evenly between the participants. Any money participants did not contribute was theirs to keep. After reading the instructions participants answered the following question: "How much money do you decide to put into the shared pot?", with possible responses ranging from $\$ 0$ to $\$ 10$ (with no option of entering fractions). The payoff from the shared pool for each random pairing was computed and the appropriate amount was paid out to each participant as a bonus payment.

\section{Results}

Manipulation check. Participants in the anger conditions reported feeling significantly more angry $(M=4.45, S D=2.18)$ than participants in the neutral conditions $(M=2.63, S D=$ 1.73), $F(1,183)=39.27, p<.001$, indicating that our manipulation was effective.

Contribution. A $2 \times 2$ between-subjects ANOVA on amount contributed showed a main effect of self-emotion, $F(1,181)=4.71, p<.05, \eta^{2}=.04$. See Table 2 for means and standard deviations. There was no effect of other-emotion, $F(1,181)=.51, n s$. The interaction did not reach statistical significance, $F(1,181)=3.44, p<.10$. A closer examination using pairwise comparisons indicated that the effects were driven by the self-anger/other-anger condition. The contribution by the self-anger/other-anger group was significantly lower than that of the self- 
neutral/other-neutral group, $t(84)=1.67, p<.05$, significantly lower than that of the selfneutral/other-anger group, $t(82)=2.33, p<.05$, and lower than that of the self-anger/otherneutral group, $t(89)=1.49, p<.10$. There was no significant difference between the selfneutral/other-neutral, self-neutral/other-anger, and self-anger/other-neutral groups, $t(181)=.76$, $n s$. Overall, the evidence supports Hypothesis 2, though not decisively. The apparent main effect of own emotional state is an artifact of the interaction: Amount contributed apparently declines only when both the individual and his or her partner are angry.

\section{---INSERT TABLE 2 HERE---}

\section{Discussion}

These findings suggest that the broadly held belief found in Study 1a - that angry participants will contribute less to the shared pool - is partially in error. In Study 1b, only angry participants contributed less when they knew that their partner was also angry. Emotionally neutral participants contributed essentially the same amount to the shared pool (approximately half their endowment) whether their partner was angry or neutral. This is consistent with our theoretical framework in general, and specifically with Hypothesis 2. If one participant is emotionally neutral, it could be that he or she is less likely to take the partner's emotional state into consideration, so the lay theory is not applied. The only condition in which the lay theory appears to predict behavior is when angry individuals are paired with other angry individuals. We theorize that angry participants are more likely to take their partners' emotional state into consideration. If the partner is neutral, the angry participant predicts that the neutral partner will make a moderate contribution (as shown in Study 1a) and contributes the same. However, if the partner is angry, the angry participant predicts that the angry partner's contribution will be reduced and matches this lower level of contribution. Anger thus appears to play two roles: The 
first in sharpening consideration of the partner's emotional state, and the second in applying the (flawed) lay theory that anger reduces cooperation.

We find this to be an interesting, and potentially important, finding. However, the interaction did not reach statistical significance. Concern about replicability is especially high when the study is of low statistical power, and the test statistic barely meets the chosen p-value (Cumming, 2012; Lindsay, 2015). While we do not have a good estimate of power in Study 1b, the somewhat conflicting statistical results for the predicted interaction (marginally significant by ANOVA, significant by pairwise comparisons) suggest a good case for attempting a conceptual replication. Thus, we decided to probe the robustness of these findings with conceptual replications using a different interface, participant population, and incentives (Studies $2 \mathrm{a}$ and $2 \mathrm{~b}$ ), and a modified methodology and procedure (Study 2b). These replications are described in the following section.

\section{Study 2a}

\section{Participants and Procedure}

The sample comprised 201 participants from the United States $\left(57.2 \%\right.$ female, $M_{\text {age }}=$ 35.82), recruited from Amazon Mechanical Turk (MTurk; Paolacci and Chandler, 2014). As before participants were randomly assigned to one of four conditions in a 2 (own emotion) $\times 2$ (emotion of partner) between-subjects design. Participants first completed an emotion induction, followed by a manipulation check. They then read a description of the SPPG and predicted how much their partner would contribute.

Self-emotion manipulation. Both anger and a neutral state were experimentally induced by the writing task used in Studies $1 \mathrm{a}$ and $1 \mathrm{~b}$.

Manipulation check. We used the same manipulation check employed in Studies 1a and 
$1 b$, averaging the anger items $(\alpha=.94)$.

Other-emotion manipulation. We randomly paired each participant with another participant who was also taking the study through MTurk. All participants were told that their identity and their partner's identity would remain anonymous, except for the partners' emotional state, which was presented directly: "Here is the information about the person you are paired with". Participants in the other-anger condition read: "current feeling: anger", while those in the other-neutral condition read: "current feeling: neutral".

Expectations of other's contribution. As in Study 1a, participants read about the SPPG. The initial endowment for each participant was reduced to 100 cents to fit the smaller payments typically made in the MTurk system (Goodman et al., 2013). Otherwise, the hypothetical game described was identical to that used in Study 1a. After reading the description of the SPPG, all participants answered the following question: "How much money do you expect the other person to put into the shared pot?", with possible responses ranging from zero to 100 cents.

\section{Results}

Manipulation check. Participants in the anger conditions reported feeling significantly more anger $(M=5.39, S D=2.48)$ than participants in the neutral conditions $(M=1.91, S D=$ $1.29), F(1,199)=158.44, p<.001$, confirming that our manipulation was successful.

Expectations of other's contribution. We submitted the predicted partner contribution to a between-subjects $2 \times 2$ ANOVA. See Table 1 for means and standard deviations. There was a significant main effect of other-emotion, $F(1,197)=19.15, p<.05, \eta^{2}=.10$, no effect of selfemotion, $F(1,197)=2.41, n s$, and no interaction, $F(1,197)=.79$, $n s$. As in Study 1a only the partner's emotional state, not one's own, influenced one's predictions of how much the partner would contribute. Angry partners were expected to contribute less than neutral partners, 
supporting Hypothesis 1. Figure 1 compares expected contribution between Studies 1a and 2a.

\section{---INSERT FIGURE 1 HERE---}

\section{Discussion}

These results conceptually replicate the finding from Study 1a that angry individuals are expected to be less cooperative than neutral others. This finding appears to be robust across experimental setting (online vs. lab), sample (university students vs. MTurk), and size of cash incentive (\$10 vs. \$1). In Study 2b, we introduce a further variation, using an alternative procedure for inducing emotional state, as we examine the robustness and/or replicability of the interaction effect found in Study $1 b$.

\section{Study 2b}

\section{Participants and Procedure}

The sample comprised 260 participants from the United States $\left(44.2 \%\right.$ female, $M_{\mathrm{age}}=$ 32.02), recruited from MTurk. Participants were randomly assigned to one of four conditions in a 2 (own emotion) $\times 2$ (emotion of partner) between-subjects design. They completed an emotion induction and manipulation check, and then participated in a SPPG with another anonymous participant.

Self-emotion manipulation. Harnessing the finding that anger is often the result of perceived injustice (Barclay et al., 2005), we asked participants in the anger condition to read story in which a drunk driver severely injured a young woman and later expressed no remorse. A court sentenced the driver to only a short prison term even though it was her third drunk driving accident, thus violating norms of justness and fairness. The story contained graphic descriptions of the accident, the victim's grave medical state, the court's inadequate punishment and the driver's lack of remorse. The neutral induction story was about a pair of marine biologists 
exploring ocean life near the Pacific coast.

Manipulation check. Participants in the anger condition were asked "Which emotion do you feel towards the drunk driver at this moment?" and instructed to type their answer in a text box. Participants in the neutral condition were asked, "Which emotion do you feel at this moment?" We assigned a value of one to "anger" responses if the responses included one or more of the following synonyms: "anger, mad, frustration, hatred, fury, irritation, rage, outrage, or annoyed". We assigned a value of zero to "not angry" responses if the responses included words signifying other emotions (sadness, boredom, etc.) or if one of the anger synonyms was combined with another, non-anger emotion, (e.g. sadness and anger). ${ }^{[2]}$

Other-emotion manipulation. As in Study 2a, each participant was simply told the emotional state (either anger or neutral) of the participant with whom he or she had been randomly paired.

Contribution. Participants completed the same SPPG described in Study 2a, with an initial endowment of 100 cents. They were allowed to contribute any portion of the money to a shared pot, which was then multiplied by a factor of 1.5 and split equally between the paired participants. Money not contributed, plus the split of the pot, was distributed as a bonus payment.

\section{Results}

Manipulation check. A binary logistic regression indicated that more participants in the anger conditions $(81.5 \%)$ reported feeling angry than participants in the neutral conditions $(3.8 \%), B=4.70, S E=.51$, Wald $=85.41, p<.05$, confirming that our manipulation was successful.

Contribution. A $2 \times 2$ between-subjects ANOVA on amount of money contributed showed a main effect of self-emotion, $F(1,256)=5.10, p<.05, \eta^{2}=.06$, but no significant 
effect of other-emotion, $F(1,256)=1.92$, $n s$. There was a significant interaction between selfemotion and other-emotion, $F(1,256)=8.26, p<.05$, supporting Hypothesis 2 . See Table 2 for means and standard deviations. Further examination of this interaction using pairwise comparisons indicated that, as in Study $1 \mathrm{~b}$, the interaction was driven by self-anger/other-anger condition. Mean contribution by the self-anger/other-anger group was significantly lower than that of the self-neutral/other-neutral group, $t(128)=2.46, p<.05$, the self-neutral/other-anger group, $t(128)=3.63, p<.05$, and the self-anger/other-neutral group, $t(128)=3.03, p<.05$. There were no significant differences between the self-neutral/other-neutral, self-neutral/other-anger, and self-anger/other-neutral groups, $t(256)=.10, n s$. As in Study $1 \mathrm{~b}$, this result fits with our theoretical framework that angry individuals only cooperate less when their partner is angry. See Figure 2 for a comparison of mean actual money contributions between Studies $1 \mathrm{~b}$ and $2 \mathrm{~b}$.

---INSERT FIGURE 2 HERE---

\section{Discussion}

In support for our model, these findings are consistent with those in Study 1b using a different population, a different interface, different manipulations of emotional states, and a different incentive structure. Once again, the results suggest that when considering actual cooperative behavior rather than expectations, there is an effect of both participants' emotional states. In both Study $1 \mathrm{~b}$ and $2 \mathrm{~b}$, the only condition that decreased actual cooperation was when angry individuals were paired with other angry individuals. This supports our propositions that individuals in this self-anger/other-anger condition are the only ones who apply the lay theory of cooperation that angry individuals are less likely to cooperate than neutral individuals.

\section{GENERAL DISCUSSION}

This study extends research on emotion and cooperation, especially in addressing the 
unique effects of anger. Past research on emotions and cooperative behavior has focused on integral emotions as opposed to incidental emotions (e.g., Adam et al., 2010; Han et al., 2007) and multi-round negotiations as opposed to single-round tasks (e.g., Van Kleef et al., 2004a; 2004b). Within the framework of the EASI model, we examined the cooperative behavior of neutral individuals paired with neutral individuals, neutral individuals paired with angry individuals, angry individuals paired with neutral individuals and angry individuals paired with angry individuals. Comparing these four groups allowed for a deeper and more systematic analysis of anger, and bridging research on other-oriented emotions and lay theories of anger provided the foundation for our predictions and findings. Across four studies using different samples, interfaces, incentives, manipulations, and structures we found evidence for an expectation that angry individuals will cooperate less than neutral individuals (1a and 2a), but that cooperation only actually decreases in situations where both parties are angry (1b and $2 b$ ). We propose that because angry individuals are more likely to take into account the role of others in their behaviors, they are more inclined to rely on their lay theories of anger (i.e., how they expect angry people to behave) and then cooperate accordingly.

Our findings suggest that the patterns observed in multi-round negotiations might not apply to single-round tasks. More specifically, the emotion of the partner does not appear to matter as much in single-round tasks as it does in negotiations or bargaining. This is supported by the finding that the cooperation of neutral individuals did not differ significantly based upon the partner's emotional state. We attribute this to a weakened "shadow of the future" in which participants do not have to worry about interacting with the partner again. Thus, when examining the role of anger in cooperation, conflict, negotiation, and bargaining, it is important to specify the degree of interaction between partners. 
We also show that anger unrelated to the task at hand (i.e., incidental anger) can spill over to affect cooperation in a different setting. Specifically, incidental anger appears to reduce cooperation only when one's partner is also angry. Notably, incidental anger did not reduce cooperation when one's partner was in a neutral state. By examining incidental rather than integral anger we can be more confident in saying that it is the feelings of anger that are responsible for changes in cooperation and not some other aspect of the situation. Thus, we believe our work complements existing research on integral anger in multi-round negotiations by showing that in simple, one-round decision tasks, neither pure anger nor the knowledge of the other person's anger decreases cooperation alone. Rather, it is the two forces jointly - both partners' anger - that lower cooperation. In doing so we also identify one context in which anger's effects are not always as negative as its reputation would predict (Anderson and Bushman, 2002). Past research has tended to focus on the damaging effects of anger on riskiness, aggression, counterproductive work behaviors and unethical decision making (Fox and Spector, 1999; Kligyte et al., 2013; Lerner and Keltner, 2001). Here we show that incidental anger alone is not a destructive force in single-round cooperative settings.

In addition, we found evidence that lay theories of anger and cooperation are not entirely accurate. Though there is an expectation that anger decreases cooperation, that is not always the case, as indicated above. Our findings contribute to a nascent literature examining the accuracy of lay theories. For instance, Cooper et al. (2015) found that lay theories of personality-behavior links are often inaccurate, leading those who hold them to suboptimal behaviors. Holding inaccurate lay theories has important implications. If, for example, an individual expects that anger leads people to behavior uncooperatively, then knowing that his or her partner is angry could lead the individual to anticipatory strategic withholding of cooperation. 
Our findings also have implications for the negotiations literature. Negotiation is the process through which two or more independent parties reach an agreement (Barry and Oliver, 1996; Caputo, 2013; Rivers, 2014). Cooperation is, clearly, highly valuable in such a process. Willingness to cooperate with other parties can smooth and expedite the path to consensus. Cooperative behavior implies a desire to reach an end state that benefits all, which is also a primary goal of a negotiation (Pruit, 1981; Rand et al., 2009). A cooperative atmosphere also permits a pleasanter negotiation climate than a competitive one (Lewicki et al., 1994). A metaanalysis (De Dreu et al., 2000) showed that individuals with a more prosocial or cooperative motivation engaged in more problem-solving, exhibited less contentious behavior, and achieved higher joint gains in negotiations than individuals with more egoistic or competitive motivations. Past scholars have documented inconsistent results regarding when expressing anger pays off and when it backfires in a negotiation (Van Kleef et al., 2008). In tackling this question, researchers have identified moderators that shed light on prior mixed findings (Steinel et al., 2008; Van Kleef and Côté, 2007). Our results suggest that the application of (inaccurate) lay theories could also be partially responsible for these varied effects. Perhaps examining other potentially incorrect lay theories in negotiation contexts may be fruitful. Furthermore, our results suggest that incidental emotions can significantly influence negotiation outcomes in addition to integral emotions.

Practically, these results suggest that managers should observe angry employees closely with prudence and attention (Gibson and Callister, 2010). Organizations might not necessarily risk damage by assigning angry employees to complete tasks requiring cooperation with nonangry employees, assuming that the anger was the result of a non-related situation. However, if both employees are angry, managers should take care to prevent them from interacting 
extensively. In sum, when assigning employees to tasks requiring cooperation, managers should take heed of their current emotional state.

These studies share some of the usual limitations of experiments using student participants working on problems for small rewards (Dipboye and Flanagan, 1979; Gordon et al., 1986; Greenberg, 1987). We tried to offset some of these limitations by using non-student respondents, at least modest financial incentives, and by conceptually replicating our findings across different samples and using modified procedures. However, future research should determine whether the causal relations identified here generalize to realistic work environments. Experience sampling methodology (Fisher and To, 2012) capitalizes on the advantages of both lab and field studies and could be valuable in extending research to the relationship between anger and cooperation in actual organizational settings.

Another limitation to our work is that we only examine anger. While we restricted our scope of research to anger for several reasons (see Introduction), we are unable to make any claims regarding several other negatively valenced emotions such as sadness, anxiety, and guilt. We also only examined only a simplified version of anger - anger without context. No reason was given for the partner's anger. It is possible that when both parties are angry for the same reason, cooperation could increase significantly. The main tenet of social identity theory is that individuals derive part of their self-concept from membership in certain groups (Ashforth and Mael, 1989; Chi et al., 2004; Han and Harms, 2010; Hogg and Terry, 2000; Tajfel, 1974). A shared anger source communicates that individuals are similar in their experience of anger (e.g., two employees are angry at the same manager for treating them both disrespectfully). A shared source of anger could create a common bond between two strangers akin to the bond between an individual and members of his or her in-group. Individuals angry for the same reason would thus 
be members of the same in-group and should act more favorably towards one another.

It is important to note that we did not test specific mechanisms. That is, we did not provide empirical evidence confirming that angry individuals are more likely to consider the role of others in their cooperative behavior, and in doing so apply a lay theory that angry individuals are less cooperative than neutral individuals. Rather, our findings are consistent with our theoretical framework. While we did find support for our hypotheses, only future research can determine whether the specific processes that we propose are indeed operating the way that we say they are.

Future research could also usefully examine how the relationships observed here progress over time. Do two individuals who bond and cooperate more because of their shared reason for anger then tend to become closer partners in the organization? Such a finding could have important implications for the workplace, as research has shown that friends outperform acquaintances on decision tasks (Jehn and Shah, 1997). This type of study would also contribute to our limited knowledge of how different individuals' emotions interact over time to affect criterion variables. A longitudinal design employing survey questions would be an appropriate way to tackle this question.

Another potential avenue for future research is identifying a range of individual differences that may determine the likelihood of cooperating with another angry person. By examining individual differences researchers can identify when a main effect is stronger, weaker or reversed, thus enriching understanding of the underlying theory and accounting for more variance in cooperation. One such difference is social value orientation (i.e., social preferences that drive behavior such as individualism, competitiveness and altruism; Van Kleef and De Dreu, 2002; Van Lange, 1999). The ability to overcome non-cooperative tendencies, bond with others, 
and cooperate effectively are crucial characteristics for positions that require negotiation, such as sales and purchasing. Identifying other relevant traits, such as emotion regulation (Gross, 1998), would certainly aid supervisors in hiring employees for such positions. For instance, the effects observed here could be diluted for individuals who tend to use emotion reappraisal strategies, which can successfully down-regulate negative emotion (Gross and John, 2003).

\section{CONCLUSION}

Across four studies, we show that in a single-round cooperation task, angry individuals paired with other angry individuals cooperate less than do other pairings of angry and neutral individuals. We propose that angry individuals, who are more likely to consider the emotional states of their partners due to an other-orientation, will apply their lay theories of anger and emotion, and adjust their cooperation accordingly. As there is a widespread belief that anger decreases cooperation, angry individuals will respond by lowering their level of cooperation when paired with other angry individuals, but not when paired with other neutral individuals. Our findings are consistent with this two-part mechanism, shed additional light on the intricate relationship between anger and cooperation, and also suggest several directions for extending the findings to the more complex interactions involved in real negotiations. 


\section{REFERENCES}

Adam, H., Shirako, A. and Maddux, W. W. (2010), "Cultural variance in the interpersonal effects of anger in negotiations", Psychological Science, Vol. 21, pp. 882-889.

Allred, K. G., Mallozzi, J. S., Matsui, F. and Raia, C. P. (1997), "The influence of anger and compassion on negotiation performance", Organizational Behavior and Human Decision Processes, Vol. 70, pp. 175-187.

Anderson, C.A. and Bushman, B. J. (2002), “Human aggression”, Annual Review of Psychology, Vol. 53, pp. 27-51.

Andreoni, J. (1995), “Cooperation in public-goods experiments: Kindness or confusion?”, American Economic Review, Vol. 85, pp. 891-904.

Ashforth, B. E. and Mael, F. (1989), "Social identity theory and the organization”, Academy of Management Review, Vol. 14, pp. 20-39.

Ashton-James, C. E. and Ashkanasy, N. M. (2008), “Affective events theory: A strategic perspective", Research on Emotion in Organizations, Vol. 4, pp. 1-34.

Averill, J. R. (1982), Anger and Aggression: An Essay on Emotion, Springer-Verlag, New York, NY.

Axelrod, R. (1984), The Evolution of Cooperation, Basic Books, New York, NY.

Bae, J. and Insead, M. G. (2004), "Partner substitutability, alliance network structure, and firm profitability in the telecommunications industry", Academy of Management Journal, Vol. 47, pp. 843-859. 
Barclay, L. J., Skarlicki, D. P. and Pugh, S. D. (2005), "Exploring the role of emotions in injustice perceptions and retaliation”, Journal of Applied Psychology, Vol. 90, pp. 629643.

Barnard, C. I. (1938), The Functions of the Executive, Harvard University Press, Cambridge, MA.

Baron, R. A., Neuman, J. H. and Geddes, D. (1999), "Social and personal determinants of workplace aggression: Evidence for the impact of perceived injustice and the Type A behavior pattern”, Aggressive Behavior, Vol. 25, pp. 281-296.

Barry, B. and Oliver, R. L. (1996), “Affect in dyadic negotiation: A model and propositions”, Organizational Behavior and Human Decision Processes, Vol. 67, pp. 127-143.

Bodenhausen, G. V., Gabriel, S. and Lineberger, M. (2000), "Sadness and susceptibility to judgmental bias: The case of anchoring", Psychological Science, Vol. 11, pp. 320-323.

Bodenhausen, G. V., Sheppard, L. A. and Kramer, G. P. (1994), "Negative affect and social judgment: The differential impact of anger and sadness", European Journal of Social Psychology, Vol. 24, pp. 45-62.

Bornstein, G. and Erev, I. (1994), "The enhancing effect of intergroup competition on group performance", International Journal of Conflict Management, Vol. 5, pp. 271-283.

Butt, A. N., Choi, J. N. and Jaeger, A. M. (2005), "The effects of self-emotion, counterpart emotion, and counterpart behavior on negotiator behavior: A comparison of individuallevel and dyad-level dynamics", Journal of Organizational Behavior, Vol. 26, pp. 681704. 
Camerer, C. (2003), Behavioral Game Theory: Experiments in Strategic Interaction, Princeton University Press, Princeton, NJ.

Caputo, A. (2013), “A literature review of cognitive biases in negotiation processes", International Journal of Conflict Management, Vol. 24, pp. 374-398.

Cavanaugh, L. A., Bettman, J. R., Luce, M. F. and Payne, J. W. (2007), “Appraising the appraisal-tendency framework", Journal of Consumer Psychology, Vol. 17, pp. 169-173.

Chi, S. C., Tsai, H. H. and Tsai, M. H. (2004), "The effects of perceived identity and justice experiences with an ADR institution on managers' decision preferences", International Journal of Conflict Management, Vol. 15, pp. 57-76.

Cooper, D. A., Connolly, T. and Kugler, T. (2015), "Lay personality theories in interactive decisions: Strongly held, weakly supported", Journal of Behavioral Decision Making, Vol. 28, pp. 201-213.

Côté, S., Hideg, I. and Van Kleef, G. A. (2013), “The consequences of faking anger in negotiations", Journal of Experimental Social Psychology, Vol. 49, pp. 453-463.

Cumming, G. (2012), Understanding the New Statistics: Effect Sizes, Confidence Intervals, and Meta-Analysis, Routledge/Taylor \& Francis Group, New York, NY.

De Dreu, C. K. and Weingart, L. R. (2003), “Task versus relationship conflict, team performance, and team member satisfaction: A meta-analysis", Journal of Applied Psychology, Vol. 88, pp. 741-749. 
De Dreu, C. K., Weingart, L. R. and Kwon, S. (2000), "Influence of social motives on integrative negotiation: A meta-analytic review and test of two theories", Journal of Personality and Social Psychology, Vol. 78, pp. 889-905.

De Hooge, I. E., Zeelenberg, M. and Breugelmans, S. M. (2007), "Moral sentiments and cooperation: Differential influences of shame and guilt", Cognition and Emotion, Vol. 21, pp. 1025-1042.

DeSteno, D., Bartlett, M. Y., Baumann, J., Williams, L. A. and Dickens, L. (2010), “Gratitude as moral sentiment: Emotion-guided cooperation in economic exchange”, Emotion, Vol. 10, pp. 289-293.

DeSteno, D., Dasgupta, N., Bartlett, M. Y. and Cajdric, A. (2004), "Prejudice from thin air: The effect of emotion on automatic intergroup attitudes", Psychological Science, Vol. 15, pp. 319-324.

Dipboye, R. L. and Flanagan, M. F. (1979), "Research settings in industrial and organizational psychology: Are findings in the field more generalizable than in the laboratory?", American Psychologist, Vol. 34, pp. 141-150.

Dugatkin, L. A., Mesterton-Gibbonsand, M. and Houston, A. I. (1992), "Beyond the prisoner's dilemma: Toward models to discriminate among mechanisms of cooperation in nature", Trends in Ecology and Evolution, Vol. 7, pp. 202-205.

Dunn, J. R. and Schweitzer, M. E. (2005), "Feeling and believing: The influence of emotion on trust”, Journal of Personality and Social Psychology, Vol. 88, pp. 736-748. 
Ellsworth, P. C. (2013), “Appraisal theory: Old and new questions”, Emotion Review, Vol. 5, pp. 125-131.

Fehr, E. and Fischbacher, U. (2004), "Social norms and human cooperation", Trends in Cognitive Sciences, Vol. 8, pp. 185-190.

Fehr, E. and Gächter, S. (2000), "Fairness and retaliation: The economics of reciprocity", The Journal of Economic Perspectives, Vol. 14, pp. 159-181.

Felson, R. B. (1992), “'Kick'em when they're down’ ”: Explanations of the relationship between stress and interpersonal aggression and violence", The Sociological Quarterly, Vol. 33, pp. 1-16.

Fessler, D. M., Pillsworth, E. G. and Flamson, T. J. (2004), “Angry men and disgusted women: An evolutionary approach to the influence of emotions on risk taking", Organizational Behavior and Human Decision Processes, Vol. 95, pp. 107-123.

Fischbacher, U., Gächter, S. and Fehr, E. (2001), “Are people conditionally cooperative? Evidence from a public goods experiment”, Economics Letters, Vol. 71, pp. 397-404.

Fisher, C. D. and To, M. L. (2012), “Using experience sampling methodology in organizational behavior", Journal of Organizational Behavior, Vol. 33, pp. 865-877.

Fitness, J. (2000), “Anger in the workplace: An emotion script approach to anger episodes between workers and their superiors, co-workers and subordinates", Journal of Organizational Behavior, Vol. 21, pp. 147-162.

Fox, S. and Spector, P. E. (1999), “A model of work frustration-aggression”, Journal of Organizational Behavior, Vol. 20, pp. 915-931. 
Gable, P. A., Poole, B. D. and Harmon-Jones, E. (2015), “Anger perceptually and conceptually narrows cognitive scope", Journal of Personality and Social Psychology, Vol. 109, pp. 163-174.

Gibson, D. E. and Callister, R. R. (2010), Anger in organizations: Review and integration", Journal of Management, Vol. 36, pp. 66-93.

Glomb, T. M. (2002), “Workplace anger and aggression: Informing conceptual models with data from specific encounters", Journal of Occupational Health Psychology, Vol. 7, pp. 20-36.

Goodman, J. K., Cryder, C. E. and Cheema, A. (2013), "Data collection in a flat world: The strengths and weaknesses of Mechanical Turk samples", Journal of Behavioral Decision Making, Vol. 26, pp. 213-224.

Gordon, M. E., Slade, L. A. and Schmitt, N. (1986), “The 'science of the sophomore' revisited: From conjecture to empiricism", Academy of Management Review, Vol. 11, pp. 191-207.

Greenberg, J. (1987), “The college sophomore as guinea pig: Setting the record straight", Academy of Management Review, Vol. 12, pp. 157-159.

Greenwald, A. G. and Banaji, M. R. (1995), "Implicit social cognition: attitudes, self-esteem, and stereotypes”, Psychological Review, Vol. 102, pp. 4-27.

Gross, J. J. (1998), “The emerging field of emotion regulation: An integrative review”, Review of General Psychology, Vol. 2, pp. 271-299.

Gross, J. J. and John, O. P. (2003), "Individual differences in two emotion regulation processes: Implications for affect, relationships, and well-being", Journal of Personality and Social Psychology, Vol. 85, pp. 348-362. 
Han, G. and Harms, P. D. (2010), “Team identification, trust and conflict: A mediation model”, International Journal of Conflict Management, Vol. 21, pp. 20-43.

Han, S., Lerner, J. S. and Keltner, D. (2007), "Feelings and consumer decision making: The appraisal-tendency framework”, Journal of Consumer Psychology, Vol. 17, pp. 158-168.

Hansen, C. H. and Hansen, R. D. (1988), "Finding the face in the crowd: An anger superiority effect”, Journal of Personality and Social Psychology, Vol. 54, pp. 917-924.

Harlé, K. M. and Sanfey, A. G. (2007), "Incidental sadness biases social economic decisions in the Ultimatum Game”, Emotion, Vol. 7, pp. 876-881.

Harmon-Jones, E., Gable, P. A. and Price, T. F. (2013), "Does negative affect always narrow and positive affect always broaden the mind? Considering the influence of motivational intensity on cognitive scope", Current Directions in Psychological Science, Vol. 22, pp. 301-307.

Hatfield, E., Cacioppo, J. T. and Rapson, R. L. (1994), Emotional Contagion, Cambridge University Press, Cambridge, UK.

Hauert, C., De Monte, S., Hofbauer, J. and Sigmund, K. (2002), "Volunteering as red queen mechanism for cooperation in public goods games", Science, Vol. 296, pp. 1129-1132.

Heide, J. B. and Miner, A. S. (1992), “The shadow of the future: Effects of anticipated interaction and frequency of contact on buyer-seller cooperation", Academy of Management Journal, Vol. 35, pp. 265-291.

Hogg, M. A. and Terry, D. I. (2000), "Social identity and self-categorization processes in organizational contexts", Academy of Management Review, Vol. 25, pp. 121-140. 
Hunter, R. J. (2001), Foundations of Colloid Science, Oxford University Press, Oxford, UK.

Huntsinger, J. R. (2013), “Does emotion directly tune the scope of attention?”, Current Directions in Psychological Science, Vol. 22, pp. 265-270.

Jehn, K. A. and Shah, P. P. (1997), "Interpersonal relationships and task performance: An examination of mediation processes in friendship and acquaintance groups", Journal of Personality and Social Psychology, Vol. 72, pp. 775-790.

Keltner, D., Ellsworth, P. C. and Edwards, K. (1993), "Beyond simple pessimism: Effects of sadness and anger on social perception", Journal of Personality and Social Psychology, Vol. 64, pp. 740-752.

Keser, C. and Van Winden, F. (2000), "Conditional cooperation and voluntary contributions to public goods", The Scandinavian Journal of Economics, Vol. 102, pp. 23-39.

Kligyte, V., Connelly, S., Thiel, C. and Devenport, L. (2013), “The influence of anger, fear, and emotion regulation on ethical decision making", Human Performance, Vol. 26, pp. 297326.

Kugler, T., Connolly, T. and Ordóñez, L. D. (2010), "Emotion, decision, and risk: Betting on gambles versus betting on people", Journal of Behavioral Decision Making, Vol. 25, pp. 123-134.

Kurzban, R. and Houser, D. (2001), "Individual differences in cooperation in a circular public goods game”, European Journal of Personality, Vol. 15, pp. 37-52.

La Porta, R., Lopez-de-Silanes, F., Shleifer, A. and Vishny, R. W. (1997), "Legal determinants of external finance", Journal of Finance, Vol. 52, pp. 1131-1150. 
Lazarus, R. S. (1991), "Progress on a cognitive-motivational-relational theory of emotion", American Psychologist, Vol. 46, pp. 819-834.

Lelieveld, G. J., Van Dijk, E., Van Beest, I., Steinel, W. and Van Kleef, G. A. (2011), "Disappointed in you, angry about your offer: Distinct negative emotions induce concessions via different mechanisms", Journal of Experimental Social Psychology, Vol. 47, pp. 635-641.

Lelieveld, G. J., Van Dijk, E., Van Beest, I. and Van Kleef, G. A. (2012), "Why anger and disappointment affect other's bargaining behavior differently: The moderating role of power and the mediating role of reciprocal and complementary emotions", Personality and Social Psychology Bulletin, Vol. 38, pp. 1209-1221.

Lerner, J. S. and Keltner, D. (2001), "Fear, anger, and risk", Journal of Personality and Social Psychology, Vol. 81, pp. 146-159.

Lerner, J. S. and Tiedens, L. Z. (2006), "Portrait of the angry decision maker: How appraisal tendencies shape anger's influence on cognition", Journal of Behavioral Decision Making, Vol. 19, pp. 115-137.

Lewicki, R. J., Litterer, J. A., Minton, J. W. and Saunders, D. M. (1994), Negotiation, Irwin, Burr Ridge, IL.

Lindsay, O. S. (2015), "Replication in psychological science”, Psychological Science, Vol. 26, pp. 1827-1832. 
Luo, Y. (2002), "Product diversification in international joint ventures: Performance implications in an emerging market”, Strategic Management Journal, Vol. 23, pp. 1-20.

Marwell, G., and Ames, R. E. (1979), "Experiments on the provision of public goods. I. Resources, interest, group size, and the free-rider problem", American Journal of Sociology, Vol. 84, pp. 1335-1360.

Milkman, K. L. (2012), "Unsure what the future will bring? You may overindulge: Uncertainty increases the appeal of wants over should", Organizational Behavior and Human Decision Processes, Vol. 119, pp. 163-176.

Montes, C., Rodríguez, D. and Serrano, G. (2012), “Affective choice of conflict management styles”, International Journal of Conflict Management, Vol. 23, pp. 6-18.

Moors, A., Ellsworth, P. C., Scherer, K. R. and Frijda, N. H. (2013), “Appraisal theories of emotion: State of the art and future development", Emotion Review, Vol. 5, pp. 119-124.

Motro, D., Ordóñez, L. and Pittarello, A. (2014, January), "Investigating the effects of anger and guilt on unethical behavior: A self regulation approach”, in Academy of Management Proceedings, Academy of Managemen.

Nair, N. (2008), “Towards understanding the role of emotions in conflict: A review and future directions", International Journal of Conflict Management, Vol. 19, pp. 359-381.

Nesse, R. M. (1990), “Evolutionary explanations of emotions”, Human Nature, Vol. 1, pp. 261289.

Norton, M. I. and Gino, F. (2014), "Rituals alleviate grieving for loved ones, lovers, and lotteries”, Journal of Experimental Psychology: General, Vol. 143, pp. 266-272. 
Nosek, B. A., Alter, G., Banks, G. C., Borsboom, D., Bowman, S. D., Breckler, S. J., Buck, S., Chambers, C. D., Chin, G., Christensen, G. and Contestabile, M. (2015), "Promoting an open research culture: Author guidelines for journals could help to promote transparency, openness, and reproducibility”, Science, Vol. 348, pp. 1422-1425.

Overbeck, J. R., Neale, M. A. and Govan, C. L. (2010), "I feel, therefore you act: Intrapersonal and interpersonal effects of emotion on negotiation as a function of social power", Organizational Behavior and Human Decision Processes, Vol. 112, pp. 126-139.

Paolacci, G. and Chandler, J. (2014), "Inside the Turk: Understanding Mechanical Turk as a participant pool", Current Directions in Psychological Science, Vol. 23, pp. 184-188.

Popper, K. R. (1959), The Logic of Scientific Discovery, Hutchinson, London, UK.

Posthuma, R. A. (2012), “Conflict management and emotions”, International Journal of Conflict Management, Vol. 23, pp. 4-5.

Pruit, D. G. (1981), Negotiation Behaviour, Academic Press, New York, NY.

Radder, H. (1996), In and About the World: Philosophical Studies of Science and Technology, SUNY Press, Albany, NY.

Rand, D. G., Dreber, A., Ellingsen, T., Fudenberg, D. and Nowak, M. A. (2009), “Positive interactions promote public cooperation", Science, Vol. 325, pp. 1272-1275.

Rivers, C. (2014), "Review of handbook of research on negotiation”, International Journal of Conflict Management, Vol. 25, pp. 322-323. 
Roland, E. and Idsøe, T. (2001), “Aggression and bullying”, Aggressive Behavior, Vol. 27, pp. 446-462.

Santos, F. C., Santos, M. D. and Pacheco, J. M. (2008), "Social diversity promotes the emergence of cooperation in public goods games", Nature, Vol. 454, pp. 213-216.

Schermerhorn, J. R. (1975), “Determinants of interorganizational cooperation”, Academy of Management Journal, Vol. 18, pp. 846-856.

Schmidt, S. (2009), "Shall we really do it again? The powerful concept of replication is neglected in the social sciences", Review of General Psychology, Vol. 13, pp. 90-100.

Shimanoff, S. B. (1984), “Commonly named emotions in everyday conversations”, Perceptual and Motor Skills, Vol. 58, pp. 514-514.

Sinaceur, M. and Tiedens, L. Z. (2006), “Get mad and get more than even: When and why anger expression is effective in negotiations", Journal of Experimental Social Psychology, Vol. 42, pp. 314-322.

Smith, C. A. and Ellsworth, P. C. (1985), "Patterns of cognitive appraisal in emotion", Journal of Personality and Social Psychology, Vol. 48, pp. 813-838.

Steinel, W., Van Kleef, G.A. and Harinck, F. (2008), “Are you talking to me?! Separating the people from the problem when expressing emotions in negotiation", Journal of Experimental Social Psychology, Vol. 44, pp. 362-369.

Stephens, D. W. and Anderson, J. P. (1997), "Reply to Roberts: Cooperation is an outcome, not a mechanism", Animal Behaviour, Vol. 53, pp. 1363-1364. 
Strack, F., Schwarz, N. and Gschneidinger, E. (1985), "Happiness and reminiscing: The role of time perspective, affect, and mode of thinking", Journal of Personality and Social Psychology, Vol. 49, pp. 1460-1469.

Syna Desivilya, H. and Yagil, D. (2005), "The role of emotions in conflict management: The case of work teams", International Journal of Conflict Management, Vol. 16, pp. 55-69.

Tajfel, H. (1974), “Social identity and intergroup behaviour”, Social Science Information, Vol. 13, pp. 65-93.

Tiedens, L. Z. and Linton, S. (2001), "Judgment under emotional certainty and uncertainty: The effects of specific emotions on information processing", Journal of Personality and Social Psychology, Vol. 81, pp. 973-988.

Todd, A. R., Forstmann, M., Burgmer, P., Brooks, A. W. and Galinsky, A. D. (2015), “Anxious and egocentric: How specific emotions influence perspective taking", Journal of Experimental Psychology: General, Vol. 144, pp. 374-391.

Underwood, G. D. (1996), Implicit Cognition, Oxford University Press, Oxford, UK.

Van Beest, I., Van Kleef, G. A. and Van Dijk, E. (2008). “Get angry, get out: The interpersonal effects of anger communication in multiparty negotiation", Journal of Experimental Social Psychology, Vol. 44, pp. 993-1002.

Van Dijk, E., Van Kleef, G. A., Steinel, W. and Van Beest, I. (2008), “A social functional approach to emotions in bargaining: When communicating anger pays and when it backfires", Journal of Personality and Social Psychology, Vol. 94, pp. 600-614. 
Van Kleef, G. A. (2010), “Don’t worry, be angry? Effects of anger on feelings, thoughts, and actions in conflict and negotiation”, in Potegal, M., Stemmler, G. and Spielberger, C. (Eds.), International Handbook of Anger, Springer, New York, NY, pp. 545-559.

Van Kleef, G. A. and Côté, S. (2007), "Expressing anger in conflict: When it helps and when it hurts”, Journal of Applied Psychology, Vol. 92, pp. 1557-1569.

Van Kleef, G. A. and De Dreu, C. K. (2002), "Social value orientation and impression formation: A test of two competing hypotheses about information search in negotiation", International Journal of Conflict Management, Vol. 13, pp. 59-77.

Van Kleef, G. A., De Dreu, C. K. and Manstead, A. S. (2004a), “The interpersonal effects of anger and happiness in negotiations", Journal of Personality and Social Psychology, Vol. 86, pp. $57-76$.

Van Kleef, G. A., De Dreu, C. K. and Manstead, A. S. (2004b), “The interpersonal effects of emotions in negotiations: A motivated information processing approach”, Journal of Personality and Social Psychology, Vol. 87, pp. 510-528.

Van Kleef, G. A., De Dreu, C. K. and Manstead, A. S. (2010), “An interpersonal approach to emotion in social decision making: The emotions as social information model", Advances in Experimental Social Psychology, Vol. 42, pp. 45-96.

Van Kleef, G. A., Van Dijk, E., Steinel, W., Harinck, F. and Van Beest, I. (2008), "Anger in social conflict: Cross-situational comparisons and suggestions for the future", Group Decision and Negotiation, Vol. 17, pp. 13-30. 
Van Lange, P. A. (1999), “The pursuit of joint outcomes and equality in outcomes: An integrative model of social value orientation", Journal of Personality and Social Psychology, Vol. 77, pp. 337-349.

Wagner, J. A. (1995), Studies of individualism-collectivism: Effects on cooperation in groups", Academy of Management Journal, Vol. 38, pp. 152-173.

Wang, L., Northcraft, G. B. and Van Kleef, G. A. (2012), "Beyond negotiated outcomes: The hidden costs of anger expression in dyadic negotiation", Organizational Behavior and Human Decision Processes, Vol. 119, pp. 54-63.

Williams, K. J. and Alliger, G. M. (1994), "Role stressors, mood spillover, and perceptions of work-family conflict in employed parents", Academy of Management Journal, Vol. 37, pp. 837-868.

Wubben, M. J., De Cremer, D. and Van Dijk, E. (2009), "When and how communicated guilt affects contributions in public good dilemmas", Journal of Experimental Social Psychology, Vol. 45, pp. 15-23.

Zammuner, V. L. (2000), “Men’s and women's lay theories of emotion”, in Fischer, A. (Ed.), Gender and Emotion: Social Psychological Perspectives, Cambridge University Press, Cambridge, UK, pp. 48-70. 


\section{ENDNOTES}

${ }^{1}$ Lay theories are different from implicit theories, which refer to unconscious or unintentional associations or evaluations about what others do (Underwood, 1996). Individuals cannot be explicitly aware of implicit beliefs and attitudes (Greenwald and Banaji, 1995). As we measure lay theories of anger and cooperation with an explicit question, we believe that lay theory is a more accurate term than implicit theory.

${ }^{2}$ We also coded the mixed emotion responses as "anger" and the results of the manipulation check did not change. 
Table 1. Means and standard deviations for expected contribution in Studies 1 a and $2 a$

\begin{tabular}{|c|c|c|c|c|c|c|c|c|}
\hline \multirow{3}{*}{$\begin{array}{l}\text { Self-emotion } \\
\text { Other-emotion }\end{array}$} & \multicolumn{4}{|c|}{ Study 1a } & \multicolumn{4}{|c|}{ Study $2 \mathrm{a}$} \\
\hline & \multicolumn{2}{|c|}{ Neutral } & \multicolumn{2}{|c|}{ Anger } & \multicolumn{2}{|c|}{ Neutral } & \multicolumn{2}{|c|}{ Anger } \\
\hline & Neutral & Anger & Neutral & Anger & Neutral & Anger & Neutral & Anger \\
\hline Expected contribution $^{\mathrm{a}}$ & $\begin{array}{c}5.54 \\
(3.12) \\
n=28\end{array}$ & $\begin{array}{c}2.60 \\
(2.83) \\
n=25\end{array}$ & $\begin{array}{c}5.67 \\
(2.97) \\
n=24\end{array}$ & $\begin{array}{c}3.60 \\
(3.38) \\
n=30\end{array}$ & $\begin{array}{c}53.21 \\
(35.94) \\
n=53\end{array}$ & $\begin{array}{c}27.45 \\
(37.78) \\
n=51\end{array}$ & $\begin{array}{c}56.46 \\
(26.94) \\
n=48\end{array}$ & $\begin{array}{c}39.39 \\
(36.54) \\
n=49\end{array}$ \\
\hline
\end{tabular}

Note. Standard deviations are in parentheses.

${ }^{a}$ Expected contribution in Study 1a is represented by a monetary amount between $\$ 0$ and $\$ 10$; expected contribution in Study $2 \mathrm{a}$ is represented by a monetary amount between 0 cents and 100 cents 
Table 2. Means and standard deviations for actual contribution in Studies $1 b$ and $2 b$

\begin{tabular}{|c|c|c|c|c|c|c|c|c|}
\hline \multirow{3}{*}{$\begin{array}{l}\text { Self-emotion } \\
\text { Other-emotion }\end{array}$} & \multicolumn{4}{|c|}{ Study 1b } & \multicolumn{4}{|c|}{ Study $2 \mathrm{~b}$} \\
\hline & \multicolumn{2}{|c|}{ Neutral } & \multicolumn{2}{|c|}{ Anger } & \multicolumn{2}{|c|}{ Neutral } & \multicolumn{2}{|c|}{ Anger } \\
\hline & Neutral & Anger & Neutral & Anger & Neutral & Anger & Neutral & Anger \\
\hline Contribution $^{\mathrm{a}}$ & $\begin{array}{c}4.15 \\
(4.17) \\
n=48\end{array}$ & $\begin{array}{c}4.80 \\
(3.59) \\
n=46\end{array}$ & $\begin{array}{c}3.96 \\
(4.10) \\
n=48\end{array}$ & $\begin{array}{c}2.47 \\
(3.65) \\
n=43\end{array}$ & $\begin{array}{c}56.82 \\
(35.32) \\
n=65\end{array}$ & $\begin{array}{c}63.02 \\
(32.12) \\
n=65\end{array}$ & $\begin{array}{c}59.38 \\
(31.72) \\
n=65\end{array}$ & $\begin{array}{c}41.65 \\
(34.96) \\
n=65\end{array}$ \\
\hline
\end{tabular}

Note. Standard deviations are in parentheses.

${ }^{a}$ Contribution in Study $1 \mathrm{~b}$ is represented by a monetary amount between $\$ 0$ and $\$ 10$; contribution in Study $2 \mathrm{~b}$ is represented by a monetary amount between 0 cents and 100 cents 


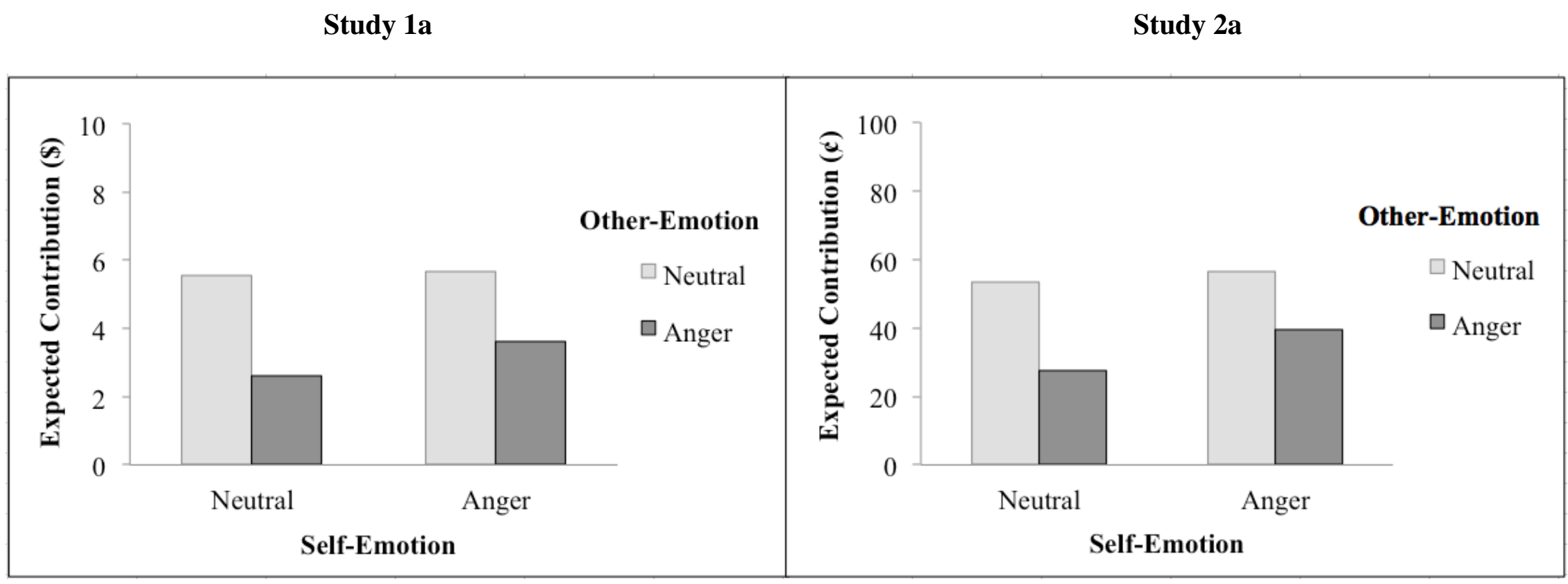

Figure 1. Mean expected amount the other person will contribute as a function of both the self's and the other's emotional states. 
Study $1 b$

Study $2 b$

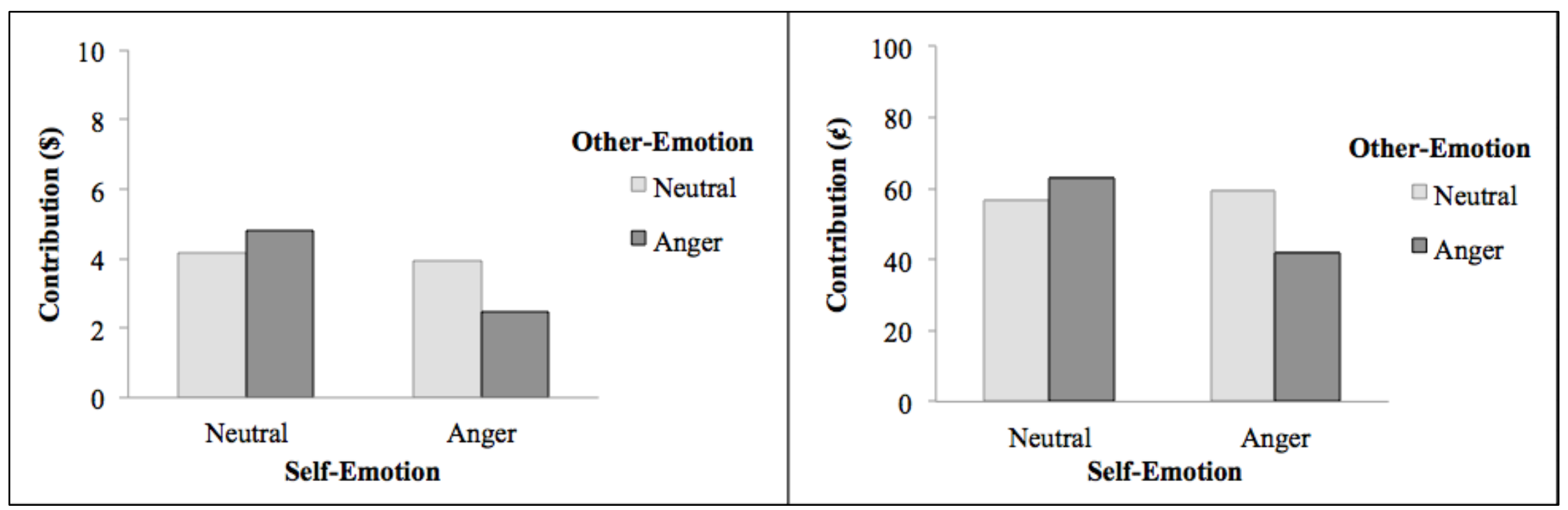

Figure 2. Mean actual contribution as a function of both the self's and the other's emotional states. 